APPENDIX 2

\title{
DOES MEDIUM-TERM EMERSION CAUSE A MASS EXTINCTION OF TIDAL FLAT MACROBENTHOS? - THE CASE OF THE TRICOLOR OIL POLLUTION PREVENTION IN THE ZWIN NATURE RESERVE (BELGIUM AND THE NeTHERLANDS)
}

Published as:

Van Colen C., Vincx M., Degraer S. (2006)

Does medium-term emersion cause a mass extinction of tidal flat macrobenthos? - The case of the Tricolor oil pollution prevention in the Zwin nature reserve (Belgium and

The Netherlands)

Estuarine, Coastal and Shelf Science 68: 343-347

\section{Abstract}

As a result of the Tricolor oil pollution in the Southern Bight of the North Sea (winter 2003) the Zwin nature reserve, consisting of tidal flats and salt marshes, was blocked from the North Sea by use of a sand barrier. Hence, macrobenthic tidal flat organisms, by nature strongly dependent on the cyclic incoming seawater, were emersed during a period of 27 days. Because the effect of medium-term emersion on the ecologically important benthic life could not be assessed beforehand, the damming was taken as an opportunity to examine these effects. This study demonstrated that (1) no species vanished due to emersion, (2) although the emersion might have caused some mortality, a mass mortality within the macrobenthos did not occur, and (3) the supra-littoral amphipods Talitrus saltator and Orchestia gammarellus performed a strong, though ephemeral immigration into the intertidal zone during the period of emersion. In view of both its minor impacts on the macrobenthos and its effectiveness in preventing 
oil pollution in the Zwin nature reserve, damming as a measure against oil pollution may be considered effective protection, especially during winter.

Keywords: Tidal flat macrobenthos, Tricolor oil pollution, Zwin nature reserve, Emersion, Mortality, Immigration

\section{Introduction}

On the $14^{\text {th }}$ December 2002, the car carrier "Tricolor" collided with the container ship "Kariba" in the English Channel and sank in French waters near the Belgian border (Fig.1). Five weeks later, on the $22^{\text {nd }}$ January 2003, approximately 170 tons of fuel leaked from the wreck of the Tricolor during salvage operations. Due to the meteorological conditions, with strong onshore winds, the oil washed ashore on French, Belgian and Dutch beaches and threatened some coastal nature reserves, including the salt marshes and tidal flats of the Zwin nature reserve.

Oil spills do have significant, though short-term negative impacts on coastal areas, whereas the effects of oil pollution in salt marshes may be measurable for years or even decades after the event (Hester \& Mendelssohn 1999). The impact of oil pollution on salt marsh vegetations is dramatic, e.g. mortality of the marsh vegetation and reduced subsequent growth (de la Cruz et al. 1981, Hester \& Mendelssohn 1999). Oil pollution in salt marshes may further reduce faunal densities by its acute, short-term toxicity (e.g. Sanders et al. 1980, McDonald et al. 1991, Widbom \& Oviatt 1994) and cause avoidance by mobile organisms (Moles et al. 1994). It was therefore proposed to protect the lagoonal Zwin salt marsh by means of a sand barrier.

Unfortunately, such a measure also excludes the tidal regime from the area, causing a permanent exposure to the air of tidal areas. Closure of intertidal areas from the natural tidal cycle can result in minor to irreversible effects on organisms and the ecosystem, depending on the time scale of the impact and the sensitivity of the organisms themselves. The macrobenthos, largely depending on the incoming water, was believed to be particularly vulnerable to an emersion 
event (Fortuin et al. 1989). Though, the mortality rate in such cases is known to depend on temperature, the duration of emersion, condition of the organisms, species identity and population structure (Hummel et al. 1994); for some species a mortality rate up to $50 \%$ per day has been found after two days of emersion.

The construction of a sand barrier as a method of protection against oil pollution therefore led to much debate in the case of the "Tricolor" calamity: the choice being between keeping out chronic oil pollution versus the risk of high mortality of the macrobenthos due to emersion. In the end, blocking both inlets by use of a sand barrier was chosen as a protective measure (Fig. 1). The entrance on the Dutch part of the nature reserve was closed for 27 days during winter (i.e. from $7^{\text {th }}$ February 2003 till $6^{\text {th }}$ March 2003).

The damming-up was taken as an opportunity to study the in situ tolerance of north-western European tidal flat macrobenthos to medium-term emersion during wintertime, with a view to making better estimates in the future whenever this measure of protection could be needed again. Two questions were therefore raised:

(1) Do common and abundant species vanish as a consequence of emersion?

(2) if not, do species vary in their responses to the disturbance of medium-term emersion?

\section{Materials \& methods}

The Zwin nature reserve $\left(51^{\circ} 21^{\prime} \mathrm{N}, 3^{\circ} 22^{\prime} \mathrm{E}\right)$ extends for $2.3 \mathrm{~km}$ along the North Sea coastline and is situated at the mouth of the Western Scheldt estuary at the Belgian-Dutch border (Fig.1). It has a total surface area of 158 ha consisting for the greatest part of salt marshes, tidal flats and tidal creek systems. This nature reserve has achieved international recognition, mainly because of its significance as important bird area (Struyf \& Degraer pers. comm.). 
Data on the distribution and diversity of the macrobenthic species and communities in the Zwin nature reserve do not exist. To be able to investigate the emersion effect on a maximum number of species, a wide variety of tidal flat habitats along a diverse creek was thus sampled. At eight sampling stations, each situated in a separate habitat, two replicate samples were collected (sampling design: 8 sites $\times 2$ replicates $\times 4$ sampling occasions; Fig. 1; Table 1).

Macrobenthic samples were collected with a hand core $(\varnothing 10 \mathrm{~cm})$ to a depth of 15 $\mathrm{cm}$ and sieved alive over a $500 \mu \mathrm{m}$ mesh sized sieve. The residual was fixed and preserved with an $8 \%$ formaldehyde-seawater solution. All macrofauna was sorted, counted and identified to the species level, except for nematodes and oligochaetes. In order to avoid biased results due to sampling methodology, species that were considered to be sampled non-representatively (max. $<1$ ind.sample ${ }^{-1}$ at the initial phase) were not taken into account for further analyses. The results presented here only take into account the common and abundant species.


Fig. 1. Study area with indication of the sampling stations (S1eS8) and the main habitat characteristics. (1) Sand barrier in the Belgian entrance creek, (2) sand barrier in the Dutch entrance creek. The Belgian (B, Belgium)eDutch ( $N$, the Netherlands) border is marked with a dotted line. X position of the "Tricolor" wreck on 14 December 2002 off the French $(F)$ coastline. 


\begin{tabular}{lcccccccc}
\hline \multicolumn{1}{c}{ Physical parameter } & \multicolumn{8}{c}{ Sampling station } \\
& $\mathbf{1}$ & $\mathbf{2}$ & $\mathbf{3}$ & $\mathbf{4}$ & $\mathbf{5}$ & $\mathbf{6}$ & $\mathbf{7}$ & $\mathbf{8}$ \\
\hline Mud content $(\%)$ & 59 & 51 & 56 & 77 & 0 & 12 & 78 & 51 \\
Median particle size $(\mu \mathrm{m})$ & 41 & 66 & 40 & 30 & 270 & 245 & 24 & 57 \\
\% time of submersion & 33 & 4 & 17 & 16 & 15 & 24 & 17 & 12 \\
\hline
\end{tabular}

Table 1. Physical parameters (median particle size $(\mathrm{mm})$, mud content $(\%)$, time of tida submersion (\%) measured at mean-tide) per sampling station.

To detect possible effects due to the emersion period, macrobenthic samples were collected three days before (B), two times during (after 12 and 21 days of emersion, E12 and E21, respectively), and 26 days after the emersion period (A), which should allow study of the subsequent mortality appearing in the first month after restoration of the natural tidal cycle (Hummel et al. 1986).

\section{Results}

In total, 14 species ( 7 annelids, 3 molluscs, 3 crustaceans and unidentified nematodes) were recorded in the area (Table 2). All species present before emersion, were encountered afterwards. No uniform clear trend was found in the density pattern during the emersion period in the study area. Total macrobenthic density increased in some stations and decreased in others (Fig. 2). The most abundant polychaetes were, in order of overall total abundance Nereis diversicolor, Heteromastus filiformis, Pygospio elegans, Streblospio benedicti, and Aphelochaeta marioni. The density of $N$. diversicolor, $H$. filiformis and $S$. benedicti generally declined strongly (minimum $23 \%$ ) during the emersion period wherever those species were present abundantly $\left(>1500\right.$ ind. $\left.\mathrm{m}^{-2}\right)$ before the construction of the sand barrier (e.g. station 4, Fig. 3). Orchestia gammarellus and Talitrus saltator were not present before and 12 days after the construction of the sand barrier. After three weeks of emersion the abundance of these organisms appeared at high levels ( $2101 \pm 1210$ ind. $\mathrm{m}^{-2}$ of O. gammarellus and $3501 \pm 2483$ 
ind. $\mathrm{m}^{-2}$ of T. saltator) at two stations near the high-water mark (S4 and S8). After the removal of the sand barrier both species were no longer recordered (Fig. 4).



Fig. 2. Total macrobenthic density. Density values ( \pm SE) before (black bar), after 12 days of emersion (grey bar), after 21 days of emersion (white bar) and 26 days after (dark grey bar) the removal of the sand barrier, per station are given.

\section{Discussion}

\section{Do common and abundant species vanish as a consequence of emersion?}

All species that were present in the study area before emersion were still present after emersion: no species vanished as a consequence of the emersion. The absence of $M$. aestuarina and L. rugicauda during the emersion is however of interest. Both species were rather rare at the initial stage (max. 1 ind.sample ${ }^{-1}$ ), therefore with a low chance of collecting these species on each sampling occasion. We were therefore unable to determine whether their absence was a real response by both species or must be considered a sampling artefact. 


\begin{tabular}{lllll} 
Species & B & E 12 & E 21 & A \\
\hline
\end{tabular}

\title{
Annelida
}

Aphelochaeta marioni
Heteromastus filiformis
Manayunckia aestuarina
Nereis diversicolor
Oligochaeta spp.
Pygospio elegans
Streblospio benedicti

$\begin{array}{rrrr}+ & + & + & + \\ + & + & + & + \\ + & - & - & + \\ + & + & + & + \\ + & + & + & + \\ + & + & + & + \\ + & + & + & +\end{array}$

\section{Crustacea}

$\begin{array}{lllll}\text { Lekanesphaera rugicauda } & + & - & - & + \\ \text { Orchestia gammarellus } & - & - & + & - \\ \text { Talitrus saltator } & - & - & + & -\end{array}$

Mollusca

\author{
Hydrobia ulvae \\ Macoma balthica \\ Scrobicularia plana
}

$\begin{array}{rrrr}+ & + & + & + \\ + & + & + & + \\ + & + & + & + \\ + & + & - & +\end{array}$

Table 2. List of observed species. Presencelabsence before (B), during (E12 and E21) and after (A) the emersion period are given: present $(+)$, absent (-).

\section{Do species vary in their responses to the disturbance of medium-term emersion?}

In general, neither the macrobenthic density nor the density of the representatively sampled species was seriously affected by the medium term emersion. In other words, a mass mortality due to the medium-term emersion was not observed. 


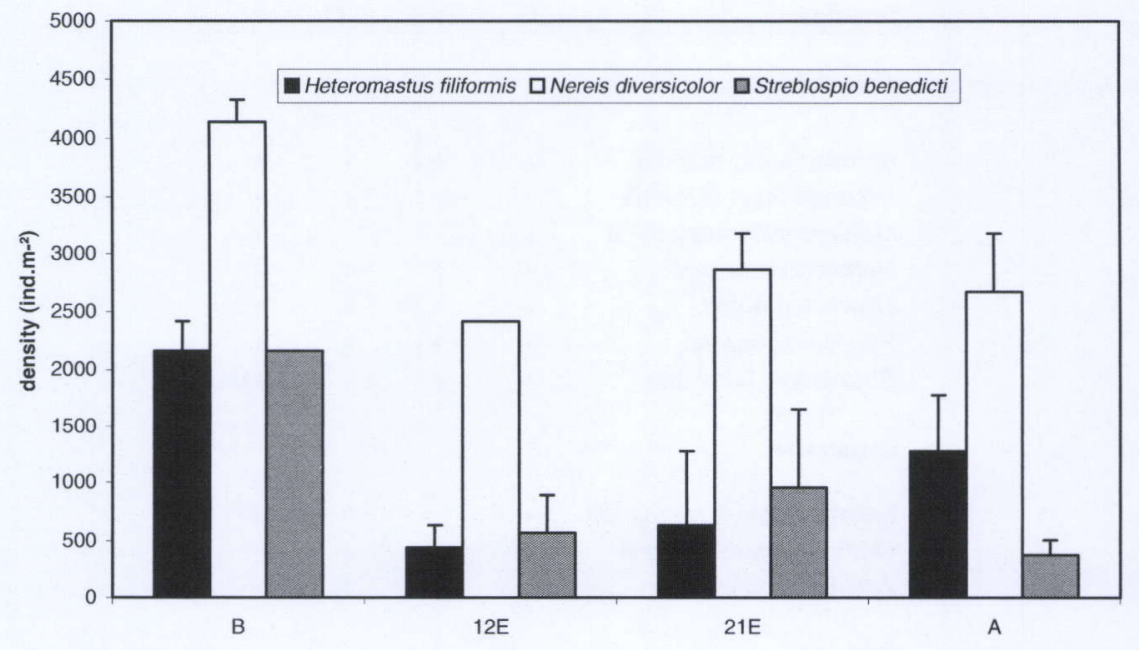

Fig. 3. Density of Nereis diversicolor, Heteromastus filiformis and Streblospio benedicti. Density values $( \pm S E)(B)$ before, (E12) after 12 days of emersion, (E21) after 21 days of emersion, and $(A) 26$ days after the removal of the sand barrier, in station 4 are given.

A consistent decrease of species-specific densities (sampling occasions E21 versus B) however was detected in those stations where the species were abundant. This may point towards mortality in the macrobenthos during the period of emersion; trends, observed in stations, where species are abundantly present, should be considered as being most representative. Unfortunately, within this study it is impossible to attribute those decreases in species-specific density to the mediumterm emersion. Because the whole study area was emersed, no control samples are available and thus the alternative hypothesis of natural winter mortality (Ysebaert 2000) cannot be rejected. Both processes might even have been acting in conjunction: in the absence of the buffering capacity of the seawater during emersion, causing major drops in bottom temperature during winter (pers. obs.), the effect of natural winter mortality might have been emphasised. Low bottom temperatures, often occurring during severe winters, are known to impact 
drastically on tidal flat macrobenthos, such as Cerastoderma edule (e.g. Beukema 1979, Dörjes 1986).



Fig. 4. Density of Talitrus saltator and Orchestia gammarellus. Total density values $( \pm S E)$ (B) before, (E12) after 12 days of emersion, (E21) after 21 days of emersion and (A) 26 days after the removal of the sand barrier are given.

The observed high resistance of the tidal flat macrobenthos to the emersion is presumably linked to the fact that this study was performed in winter. Strong seasonal differences in the sensitivity of the macrobenthos to prolonged emersion have been found (Hummel \& Bogaards 1989, Fortuyn et al. 1989). Ambient temperature is considered to be the most important factor, regulating this seasonality (Hummel et al. 1994). Hummel et al. (1988) showed that macrobenthos mortality during emersion increased progressively, with increasing temperature. As a consequence of lower temperature stress in addition to the stress from emersion, lower temperatures in winter during emersion might result in a lower mortality of the macrobenthic organisms. 
The absence of the incoming water during flood and the associated lack of food and oxygen supply during a period of emersion also imposes physiologically stressful conditions on the macrobenthos (Hummel et al. 1994). However, during disturbances (e.g. emersion), macrobenthic organisms are able to stimulate the use of their biochemical reserves (e.g. lipids, proteins and glycogen) (Bayne et al. 1985, Hummel et al. 1994). These reserves increase before winter and decrease during winter as result of nutritive stress and the reallocation of glycogen from the soma to the gonads as investment for the reproduction (Bayne et al. 1985, Hummel et al. 1994). As a consequence of both lower temperatures and physiological condition macrobenthos is known to have a lower mortality due to disturbance during periods with lower temperature (e.g. winter) (Hummel et al. 1994).

The high abundances of T. saltator and O. gammarellus after 21 days of emersion and their absence after emersion can be explained by the natural distribution of these species. Both species are found most frequently nearby the high-water mark in supra-littoral, semi-terrestrial habitats (Jones \& Wigham 1993). During the period of emersion, the tidal flats, which used to be inundated twice a day, now become a suitable for both species: an ephemeral immigration of both species into the intertidal zone during the third week of emersion from these habitats therefore seems likely.

In view of its minor impact on the macrobenthos and its effectiveness in preventing oil pollution in semi-enclosed salt marshes, such as the Zwin nature reserve, damming as a measure against oil pollution may be considered effective. Furthermore, given the long-lasting and severe impact of oil pollution in salt marshes (Hester \& Mendelssohn 1999) in contrast to the minor impact of medium-term emersion, as demonstrated here for macrobenthos during wintertime, this strategy of pollution prevention should be considered a better alternative to tolerating an oil slick, followed by a subsequent clean-up. 


\section{Acknowledgments}

The authors want to thank everybody who assisted in sampling and analysing the macrobenthic samples (Jan Wittoeck, Danny Peelaers, Bart Beuselinck, Gert Van Hoey, Sofie Vandendriessche, Annelies Goffin and Jeroen Speybroeck) and the sedimentological samples (Dannielle Schram). Valuable comments on the manuscript were provided by Tom Ysebaert (NIOO-KNAW) and three anonymous referees. We also express special thanks to Kris Struyf, conservator of the Zwin nature reserve, for his logistic support of this study. 